\title{
Regioselective Synthesis of 3-Haloalkyl-isoxazoles from the Electrophilic Cyclization of Halogenated Oximes
}

\author{
Simone Schneider Amaral ${ }^{\star,}$ and Paulo Henrique Schneider ${ }^{2}$ \\ ${ }^{1}$ Universidade Federal de Ciências da Saúde de Porto Alegre (UFCSPA), Departamento de Ciências \\ Básicas da Saúde, 90.050-170, Porto Alegre, RS, Brazil. \\ ${ }^{2}$ Universidade Federal do Rio Grande do Sul (UFRGS), Departamento de Química, 91501-970, Porto Alegre, \\ RS, Brazil. \\ *simonea@ufcspa.edu.br
}

Keywords: Electrophilic Cyclization, Haloalkyl-isoxazoles, Heterocycles.

\section{INTRODUCTION}

Heterocycles constitute a major group of organic compounds. Among the great variety of existing heterocycles, the isoxazole core stands out due to its synthetic versatility and broad spectrum of interesting biological activities. ${ }^{1}$ Additionally, the development of new strategies for synthesizing halogenated heterocycles has received much attention since the presence of such groups is often associated with improvements in pharmacological properties of organic molecules. ${ }^{2}$ From a synthetic perspective, the regio and stereoselective control for the introduction of haloalkyl substituents in heterocycles is limited. Therefore, efficient and simple methods for the straightforward synthesis of haloalkyl-isoxazoles are highly desired.

\section{RESULTS AND DISCUSSION}

Several studies showed that the electrophilic cyclization of substituted acetylenes can be an efficient way to generate many heterocycles, including isoxazoles. ${ }^{3}$ These results prompted us to evaluate such approach for the synthesis of a series of new 5-alkyl(phenyl)-3-haloalkyl-4-iodoisoxazoles (4a-4c, 5a-5c) from the electrophilic cyclization of halogenated 2-alkyn-1-one O-methyl oximes (2a-2c, 2a-2c). The procedure involves: (a) preparation of the ynones, (b) synthesis of the $O$ methyl oximes, and (c) electrophilic cyclization (Scheme 1).
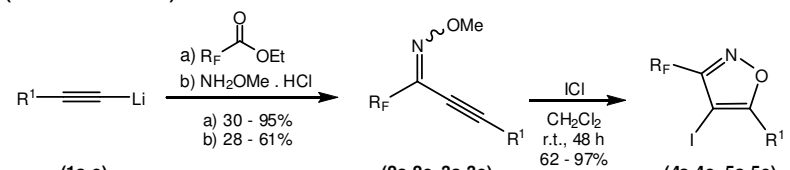

$$
\text { (1a-c) }
$$

(2a-2c, 3a-3c)

\begin{tabular}{c|ll} 
Compd. & $\mathbf{R}^{\mathbf{1}}$ & $\mathbf{R}_{\mathbf{F}}$ \\
\cline { 2 - 3 } $\mathbf{2 a}, \mathbf{4 a}$ & $\mathrm{Ph}$ & $\mathrm{CF}_{3}$ \\
$\mathbf{3 a} \mathbf{5 a}$ & $\mathrm{Ph}$ & $\mathrm{CCl}_{3}$ \\
$\mathbf{2 b}, \mathbf{4 b}$ & $\mathrm{C}_{4} \mathrm{H}_{9}$ & $\mathrm{CF}_{3}$ \\
3b, 5b & $\mathrm{C}_{4} \mathrm{H}_{9}$ & $\mathrm{CCl}_{3}$ \\
2c, 4c & $\mathrm{C}_{5} \mathrm{H}_{11}$ & $\mathrm{CF}_{3}$ \\
3c, 5c & $\mathrm{C}_{5} \mathrm{H}_{11}$ & $\mathrm{CCl}_{3}$
\end{tabular}

Some O-methyl oximes (2a-2c, 2a-2c) were isolated as a diastereoisomeric mixture. Two factors seem to be influencing this diastereoisomeric ratio: the $\mathrm{R}^{1}$ bulkiness relative to the alkyne moiety and the electron withdrawing character of $R_{F}$. In our studies, the desired $E$ isomer was always the predominant product.

The O-methyl oximes cyclization was conducted directly from the diastereosiomeric mixture and $\mathrm{ICl}$ was selected as the electrophile due to its remarkable performance in previous publications. ${ }^{3}$ The (Z)-O-methyl oximes were easily separated from the isoxazoles after cyclization from crystallization or by column chromatography on silica gel.

\section{CONCLUSION}

Our studies has shown that the synthesis of 5alkyl(phenyl)-3-haloalkyl-4-iodo-isoxazoles from the electrophilic cyclization of halogenated $(E)-4$ alkyl(phenyl)-1,1,1-trihalomethyl-3-in-2-one- $O$ methyloximes with $\mathrm{ICl}$ is very efficient and regioselective. In addition, since the isolated heterocycles are highly substituted they can be further modified in order to improve the molecule proprieties.

\section{ACKNOWLEDGEMENTS}

The authors thank the financial support and fellowships from CAPES, CNPq, FAPERGS, UFRGS and UFCSPA.

\section{REFERENCES}

1 (a) Eicher, T.; Hauptmann, S. The Chemistry of Heterocycles Structure, Reactions, Synthesis, and Applications, Willey-VHC Verlag $\mathrm{GmbH}$ and Co. KGaA, $2^{\mathrm{a}}$ ed. 2003. (b) Taldone, T.; Sun, W.; Chiosis, G, Bioorg. Med. Chem. 2009, 17, 2225.

${ }^{2}$ Taldone, T.; Sun, W.; Chiosis, G, Bioorg. Med. Chem. 2009, 17, 2225

${ }^{3}$ (a) Waldo, J. P.; Larock, R. C. Org. Lett. 2005, 23, 5203. (b) Chen, Y.;

Cho, C.-H.; Larock, R. C. Org. Lett. 2009, 11, 173.

\section{Scheme 1.}

$14^{\text {th }}$ Brazilian Meeting on Organic Synthesis $-14^{\text {th }}$ BMOS - September 01-05, 2011-Brasilia, Brazil 